\title{
ANALISIS PENGARUH BERBAGI PENGETAHUAN ORGANISASI TERHADAP KINERJA ORGANISASI: PERAN PEMEDIASI INOVASI ORGANISASI
}

\author{
Muhammad Ali Fikri \\ Universitas Ahmad Dahlan \\ muhammad.fikri@mgm.uad.ac.id
}

\begin{abstract}
The capability of an organization to conductorganizationalperformance depends on its innovation resources. This capability can be utilized by facilitating organization innovation in the organization. However, organizational innovation activities cannot be happened automatically. Therefore, knowledge sharing plays significant role to encourage organizational innovation particularly in the context of university. The main objective of this study was to analyze the mediation effect of organizational innovation on the impact of organizational knowledge sharing on organizational performance. This study uses the primary data which obtained through the survey by distributing questionnaires. The respondents from this study were employees of university in Province Daerah Istimewa Yogyakarta, who were included in the purposive sampling criteria. The questionnaires were worth to analyze as much as 75 questionnaires from 100 questionnaires. Scale test result of the instruments used in this study meet the standard of validity and reliability analysis. The results of regression analysis of this study indicate that organizational knowledge sharing has a positive effect on organizational performance, organizational knowledge sharing has a positive effect on organizational innovation, and organizational innovation has a positive effect on organizational performance. When the organizational innovation was included as a mediated variable, the effect of organizational knowledge sharing on organizational performance remains positive and significant. This means that the organizational innovation is a partial mediated in the effect of organizational knowledge sharing on organizational performance.
\end{abstract}

Keywords: organizational knowledge sharing, organizational innovation, organizational performance

\section{PENDAHULUAN}

Persaingan pada era globalisasi saat ini menuntut perusahaan atau organisasi untuk dapat mengembangkan kemampuannya dengan lebih cepat. Dalam rangka bertahan hidup, perusahaan atau organisasi tidak saja perlu memperkenalkan barang dan jasa yang baru namun juga harus menemukan cara baru dalam melakukan bisnis salah satunya yaitu dengan melakukan inovasi (Klijn dan Tomic, 2010). Inovasi dapat didefinisikan sebagai suatu bentuk kebaruan yang 
dapat ditempuh perusahaan untuk menciptakan dan mempertahankan keberlanjutan daya saing perusahaan (Johannessen et al., 2001), serta sebagai kunci keberhasilan bisnis (Nonaka dan Takeuchi, 1995).

Inovasi yang ada di dalam organisasi disebut dengan inovasi organisasi (Birkinshaw et al., 2008). Inovasi organisasi dapat berupa pengembangan produk baru, proses baru, keterampilan baru, dan manajemen baru (Klijn dan Tomic, 2010; Birkinshaw et al., 2008). Dengan melakukan inovasi, organisasi dapat mengembangkan diri melalui penciptaan produk, ide, proses, atau jasa baru yang ditawarkan ke pasar guna memperluas atau mempertahankan pangsa pasar. Kegagalan perusahaan berinovasi berakibat pada menurunnya kemampuan untuk bersaing.

Dalam melakukan inovasi, seluruh elemen organisasi dituntut mempunyai pengetahuan yang baik dan mendalam tentang konsumen yang dilayaninya (Nurmandi, 2006), sehingga pengetahuan yang ada dalam perusahaan perlu dikelola dengan baik untuk memastikan bahwa proses inovasi berjalan dengan baik. Penelitian empiris terdahulu menjelaskan bahwa berbagi pengetahuan organisasi berpengaruh positif terhadap inovasi organisasi (Allameh et al., 2014). Lebih lanjut, Davenport dan Prusak (1998) menyatakan bahwa pengetahuan merupakan faktor kunci dalam keberhasilan setiap perusahaan dan perusahaan yang mampu mengelola pengetahuannya dengan baik dapat membuat organisasi menjadi lebih inovatif. Dengan kata lain keberhasilan organisasi dalam berinovasi terletak pada kemampuannya untuk mengembangkan dan membagi pengetahuan yang dimiliki.

Penelitian ini berfokus pada pengetahuan pada tingkat individual. Hal ini dikarenakan, pengetahuan pada dasarnya melekat pada pikiran individu dan berhubungan dengan pengalaman dan interpretasi oleh individu (Davenport dan Prusak, 1998). Lebih lanjut Indarti (2010) mengemukakan bahwa pengetahuan adalah interpretasi informasi oleh pengguna informasi dengan menggunakan sejarah, pengalaman dan pola interpretasi individu itu sendiri. Oleh karena itu, interpretasi pada informasi yang sama dengan individu yang berbeda akan menghasilkan konteks pengetahuan yang berbeda pula (Indarti, 2010).

Inovasi organisasi juga dapat mempengaruhi kinerja organisasi (Tuan et al., 2016). Penelitian empiris yang dilakukan oleh Tuan et al., (2016) menjelaskan bahwa inovasi organisasi berpengaruh positif terhadap kinerja organisasi. Meskipun inovasi organisasi memiliki peranan yang penting dalam meningkatkan kinerja organisasi, namun penelitian yang dilakukan oleh Tuan et al., (2016) tersebut belum menunjukkan hasil yang konsisten sehingga penelitian untuk menganalisa pengaruh positif inovasi organisasi pada kinerja organisasi perlu dilakukan secara lebih mendalam. Tuan et al., (2016) menambahkan sebuah penelitian untuk menganalisa pengaruh positif inovasi organisasi pada kinerja organisasi merupakan suatu hal yang menarik untuk dikaji lebih dalam karena secara eksplisit inovasi organisasi dapat meningkatkan kinerja organisasi.

Berbagi pengetahuan organisasi juga dapat mempengaruhi kinerja organisasi (Chiu dan Chien, 2015). Semakin individu membagi pengetahuannya, maka semakin tercipta pengetahuan baru yang berguna untuk peningkatan kinerja organisasi tersebut (Chiu dan Chien, 2015). Pengetahuan harus dapat diakses dan digunakan oleh banyak individu agar fungsi pengetahuan tersebut lebih efektif sehingga dibutuhkan adanya berbagi pengetahuan. Berbagi pengetahuan antar individu di dalam organisasi adalah proses memindahkan pengetahuan yang dimiliki oleh satu individu kepada individu 
lain di dalam organisasi sehingga pengetahuan tersebut dapat dimengerti dan digunakan oleh banyak individu (Ipe, 2003). Lebih lanjut, Van den Hoof (2004) menyatakan bahwa nilai dari pengetahuan akan semakin meningkat jika pengetahuan tersebut dibagi karena dengan berbagi pengetahuan akan memberikan manfaat yang lebih banyak bagi individu. Selain itu, berbagi pengetahuan juga akan menciptakan pengetahuan baru (Xue et al., 2011). Tuan et al., (2016) menekankan bahwa inovasi organisasi mampu berperan sebagi pemediasi potensial pada pengaruh positif berbagi pengetahuan organisasi terhadap kinerja organisasi karena praktik berbagi pengetahuan berperan penting pada penerapan dan penciptaan inovasi organisasi dalam suatu organisasi yang pada akhirnya dapat mempengaruhi kinerja organisasi.

Berdasarkanpendekatan pemahamanyang dilakukan melalui beberapa penelitian terdahulu tersebut dan secara metodologi telah memenuhi konsep mediasi yang dikemukakan oleh Baron dan Kenny (1986), yaitu adanya penelitian mengenai; pengaruh berbagi pengetahuan organisasi terhadap kinerja organisasi (Chiu dan Chien, 2015); pengaruh berbagi pengetahuan organisasi terhadap inovasi organisasi (Allameh et al., 2014), dan pengaruh inovasi organisasi terhadap kinerja organisasi (Tuan et al., 2016), maka peneliti menduga inovasi organisasi memungkinkan menjadi variabel pemediasi pada pengaruh positif berbagi pengetahuan organisasi terhadap kinerja organisasi. Secara konseptual, penelitian ini dimaksudkan untuk menganalisa pengaruh positif berbagi pengetahuan organisasi terhadap kinerja organisasi dengan inovasi organisasi sebagai variabel pemediasi.

Penelitian ini dilakukan pada konteks organisasi pendidikan khususnya di universitas. Universitas adalah organisasi pendidikan yang sangat lekat dengan pengetahuan (Fullwood et al., 2013).Adanya beberapa macam pengetahuan yang terdapat pada universitas, menjadikan universitas sebagai organisasi di bidang pendidikan yang mempunyai aktivitas berbagi pengetahuan yang paling maksimal (Mathew, 2010). Universitas akan menggunakan banyak aktivitas berbagi pengetahuan untuk membantu mengembangkan, memproduksi ulang dan memperbaiki sumber daya pengetahuan (Mathew, 2010). Oleh karena itu, penelitian tentang berbagi pengetahuan di universitas sangatlah penting karena akan membantu memperbaiki proses pengajaran, pembelajaran dan memberikan dasar pengetahuan yang kuat untuk keperluan penelitian lainnya (Ramachandran et al., 2009).

Alasan lain mengapa berbagi pengetahuan di universitas itu penting karena semua pegawai yang ada di universitas sangat lekat akan hal tentang pengetahuan dan membutuhkan aktivitas berbagi pengetahuan untuk mendukung tugasnya masing-masing (Fullwood et al., 2013). Tenaga kerja yang ada di universitas terbagi atas tenaga kerja akademik yaitu para dosen dan tenaga kerja non akademik yaitu pegawai administrasi dan teknisi (Abdullah et al., 2000). Semua tenaga kerja yang bekerja di universitas disebut dengan pekerja pengetahuan (knowledge worker) karena mayoritas mereka bekerja di universitas selalu berhubungan dengan pengetahuan (Trehan dan Kushwaha, 2012).

Untuk memudahkan penelitian, data penelitian tidak diambil dari universitas di seluruh Indonesia tetapi hanya beberapa universitas yang ada di Provinsi Daerah Istimewa Yogyakarta yang terkenal sebagai kota pelajar dan kota pendidikan. Banyaknya universitas dengan kualitas yang baik menjadikan kota Yogyakarta sebagai kota tujuan untuk melanjutkan pendidikan. Subyek penelitian ini adalah dosen yang bekerja di Universitas di Provinsi D.I Yogyakarta.

Berbagi pengetahuan antar dosen maupun rekan kerja lain akan membantu dosen dalam menyelesaikan tugas-tugas tersebut (Jolaee et 
al., 2013). Dosen yang dapat bekerja sama dan berkolaborasi dengan dosen maupun rekan kerja lain akan dapat meningkatkan kualitas dari penelitian yang dilakukan serta memberikan kontribusi pada perkembangan pengetahuan (Kidwell et al., 2000). Selain itu, dosen yang saling berbagi pengetahuan dapat mengembangkan potensi yang ada di dalam diri dosen tersebut menjadi lebih bermanfaat, meningkatkan kinerja dan produktifitasnya (Saad dan Haron, 2013).

Berdasarkan data dari situs www.forlap. dikti.go.id, sampai tahun 2016 Provinsi D.I Yogyakarta mempunyai 24 universitas yang terdiri dari universitas negeri maupun swasta dengan total jumlah dosen sebanyak 14.982 orang. Banyaknya jumlah dosen tersebut mengindikasikan terdapat berbagai macam latar belakang, karakteristik danjuga kepribadian dosen yang berbeda-beda yang dapat memudahkan peneliti dalam melakukan penelitian.

Berdasarkan permasalahan penelitian di atas, dapat diidentifikasi tujuan penelitian sebagai berikut: pertama, untuk menguji pengaruh positif berbagi pengetahuan organisasi terhadap kinerja organsiasi. Kedua, untuk menguji peran pemediasi inovasi organisasi pada pengaruh positif berbagi pengetahuan organisasi terhadap kinerja organisasi.

\section{REVIEW LITERATUR DAN HIPOTESIS}

\section{Berbagi Pengetahuan Organisasi}

Nonaka dan Takeuchi (1995) mengatakan bahwa dalam manajemen pengetahuan terdapat konsep dasar yaitu bahwa pengetahuan dapat dibagi. Kemampuan perusahaan untuk secara efektif memanfaatkan pengetahuan sangat tergantung pada individu-individu didalamnya, yang membuat pengetahuan, berbagi, dan menggunakan pengetahuan (Ipe, 2003). Selanjutnya Ipe (2003) menjelaskan bahwa memanfaatkan pengetahuan hanya mungkin apabila orang dapat berbagi pengetahuan yang mereka miliki dan membangun pengetahuan orang lain.

Hal senada disampaikan Liao et al. (2006) untuk menentukan fokus dari manajemen pengetahuan, organisasi harus fokus pada berbagi pengetahuan. Lebih lanjut Liao et al., (2006) menjelaskan bahwa berbagi pengetahuan merupakan proses penting dalam organisasi pada saat ini. Berbagi pengetahuan dianggap sukses dalam menghasilkan modal intelektual bersama, sebuah sumber yang semakin penting. Berbagi pengetahuan menurut Liao et al., (2006) merupakan proses dimana orang lain dengan sukarela menyumbangkan pengetahuan mereka dan bersemangat mengumpulkan pengetahuan dari orang lain yang dibutuhkan, yang selanjutnya akan menciptakan siklus berbagi pengetahuan dalam organisasi. Berbagi pengetahuan dalam konteks penelitian ini dapat didefinisikan sebagai proses interaksi yang terjadi antar anggota organisasi untuk saling berbagi informasi atau pengetahuan. Hal ini dilakukan untuk meningkatkan inovasi organisasi melalui penciptaan pengetahuan baru dalam organisasi.

\section{Inovasi Organisasi Sebagai Bentuk Kebaruan}

Inovasi berkembang menjadi bagian dari hidup perusahaan sebagai sarana untuk menunjukkan kemampuan daya saing dan kunci meraih kesuksesan (Nonaka \& Takeuchi, 1995). Definisi dari inovasi sangat beragam tetapi mengacu pada satu simpulan yaitu inovasi sebagai bentuk kebaruan. Indarti (2010) mengungkapkan bahwa apa yang menjadi kebaruan dalam inovasi di dalam organisasi adalah keluaran dari kegiatan operasional perusahaan yang dianggap baru oleh organisasi. Oleh karena itu, kemampuan inovasi organisasi dapat diukur dari kemampuan organisasi menghasilkan bentuk kebaruan sebagai hasil kegiatan operasional organisasi (Indarti, 2010). 
Berbicaramengenai inovasi, inovasibukan hanya saja merupakan suatu bentuk kebaruan yang berupa produk atau jasa tetapi juga kebaruan dalam bentuk tata kelola inovasi organisasi (Birkinshaw et al., 2008). Menurut Schumpeter (1934) dalam Indarti (2010) menjelaskan inovasi organisasi sebagai pengenalan suatu yang baru, pendahuluan metode produksi baru, membuka pasar baru, membuka sumber pasokan baru, sehingga organisasi mampu melaksanakan konsep inovasi organisasi yang baru dari industri apapun. Demikian pula, Lundvall (1992) menjelaskan bahwa inovasi organisasi sebagai proses yang berkelanjutan atau eksplorasi yang dihasilkan dalam bentuk: 1) produk baru, 2) teknik-teknik baru, 3) bentuk organisasi baru, dan 4) pasar baru.

\section{Kinerja Organisasi}

Penggunaan kata kinerja organisasi secara luas sering digunakan dalam lingkup manajemen, baik scholars, pemimpin organisasi, atau manajer. Meskipun konsep kinerja organisasi penting, namun secara luas diakui bahwa hal ini juga menjadi masalah penting bagi para peneliti karena belum ada kesepakatan pada terminologi dasar dan definisi dari kinerja organisasi (Liao dan $\mathrm{Wu}, 2009$ ).

Kinerja organisasi dapat didefinisikan sebagai refleksi dari pencapaian keberhasilan organisasi dari berbagai aktivitas yang dilakukan oleh perilaku organisasi dan perilaku individuindividu yang ada di dalamnya (Venkatraman dan Ramanujam, 1986). Kinerja organisasi merupakan tindakan-tindakan atau kegiatan yang dapat diukur (Waterhouse \& Svendsen, 1998) dan untuk mengukur kinerja organisasi dibutuhkan pengukuran kinerja organisasi (Delaney dan Huselid, 1996). Dalam literatur management control system, Anthony dan Govindarajan (2001) mendefinisikan pengukuran kinerja organisasi sebagai pengukuran atas hasil dari implementasi strategi dan hasil kinerja yang dianggap baik sehingga dapat menjadi standar untuk mengukur kinerja di masa mendatang. Selanjutnya dapat dikatakan bahwa apabila indikator yang menjadi pengukuran kinerja organisasi meningkat, berarti strategi telah diimplementasikan dengan baik (Anthony dan Govindarajan, 2001). Pengukuran kinerja memainkan peranan penting dalam membangun rencana strategik, mengevaluasi pencapaian tujuan organisasi, dan mengkompensasi manajer (Anthony dan Govindarjan, 2001).

Para ahli sepakat bahwa pengukuran kinerja organisasi sebaiknya tidak hanya menggunakan satu ukuran tunggal yaitu ukuran kinerja keuangan (Delaney \& Huselid, 1996). Meskipun kinerja keuangan masih dianggap sebagai aspek utama dalam penilaian kinerja organisasi, namun penilaian dengan kinerja keuangan belum mencukupi untuk dapat menjelaskan keefektifan organisasional secara umum sehingga dibutuhkan penilaian nonkeuangan (Delaney dan Huselid, 1996).

Dari penjelasan diatas dapat disimpulkan bahwa pengukuran kinerja organisasi melalui non-keuangan perlu dilakukan oleh organisasi karena dapat menyelaraskan strategi perusahaan ke dalam berbagai tujuan strategis yang lebih spesifik. Lebih lanjut, Demirbag et al. (2007) mengungkapkan bahwa pengukuran kinerja keuangan dan non-keuangan pada suatu perusahaan merupakan hal penting bagi perbaikan kinerja organisasi. Penelitian ini menggunakan ukuran kinerja keuangan dan non keuangan sebagai indikator keberhasilan dari kinerja organisasi yang telah dilakukan.

\section{HASIL PENELITIAN DAN PEMBAHASAN}

\section{Pengaruh Positif Berbagi Pengetahuan Organisasi Terhadap Kinerja Organisasi}

Pengetahuan sebagai aset penting dalam menciptakan pertumbuhan yang berkelanjutan 
dan keunggulan kompetitif organisasi apabila organisasi mampu mengidentifikasi, menangkap dan memanfaatkan pengetahuan dalam organisasi dengan baik (Nonaka dan Takeuchi, 1995; Grant, 1996). Menurut teori berbasis pengetahuan yang dikemukakan oleh Grant (1996), berbagi pengetahuan yang merupakan proses dalam manajemen pengetahuan akan memberikan hasil berupa kinerja individual. Berbagi pengetahuan di dalam organisasi disebut dengan berbagi pengetahuan organisasi. Penelitian empiris yang telah dilakukan oleh Chiu dan Chien (2015) membuktikan bahwa aktivitas berbagi pengetahuan organisasi berpengaruh positif terhadap kinerja organisasi. Berbagi pengetahuan akan memberikan kesempatan bagi individu untuk saling bertukar ide, informasi, pengetahuan serta ikut aktif dalam kegiatan yang membutuhkan kerja sama sehingga kinerja individual dan kinerja organisasi akan semakin meningkat.

Berdasarkan pernyataan di atas dapat disimpulkan bahwa aktivitas berbagi pengetahuan organisasi dapat meningkatkan kinerja organisasi pada organisasi. Berdasarkan uraian tersebut dapat ditarik hipotesis pertama yaitu:

$$
\begin{array}{ll}
\mathrm{H}_{1} \text { : } & \begin{array}{l}
\text { Berbagi pengetahuan organisasi } \\
\text { berpengaruh positif terhadap kinerja } \\
\text { organisasi. }
\end{array}
\end{array}
$$

\section{Peran Inovasi Manajemen Sebagai Variabel Pemediasi}

Inovasi organisasi mengacu perubahan cara dalam menata kelola organisasi manajemen dengan meninggalkan proses organisasi, praktik organisasi, struktur organisasi yang sudah tidak sesuai dalam memenuhi tuntutan organisasi, kebutuhan organisasi dan permintaan stakeholder (Hamel, 2006). Inovasi organsiasi dapat dipengaruhi oleh berbagi pengetahuan. Penelitian empiris terdahulu menjelaskan bahwa berbagi pengetahuan organisasi berpengaruh positif terhadap inovasi organisasi (Allameh et al., 2014). Lebih lanjut, Davenport dan Prusak (1998) menyatakan bahwa pengetahuan merupakan faktor kunci dalam keberhasilan setiap organisasi dan organisasi yang mampu mengelola pengetahuannya dengan baik dapat membuat organisasi menjadi lebih inovatif. Dengan kata lain keberhasilan organisasi dalam berinovasi terletak pada kemampuannya untuk mengembangkan pengetahuan.

Inovasi organisasi juga dapat berpengaruh positif dalam meningkatkan kinerja organisasi (Tuan et al., 2016). Lebih lanjut Tuan et al., (2016) mengungkapkan bahwa inovasi organisasi merupakan sarana dalam meningkatkan keunggulan kompetitif suatu organisasi yang pada akhirnya dapat meningkatkan kinerja organisasi. Tuan et al., (2016) menekankan bahwa inovasi organisasi mampu berperan sebagi pemediasi potensial pada pengaruh positif berbagi pengetahuan organisasi terhadap kinerja organisasi karena praktik berbagi pengetahuan berperan penting pada penerapan dan penciptaan inovasi organisasi dalam suatu organisasi yang pada akhirnya dapat mempengaruhi kinerja organisasi. Berdasarkan hal tersebut di atas, dapat dirumuskan hipotesis sebagai berikut:

$\mathrm{H}_{2}$ : Inovasi organisasi memediasi pengaruh positif pada berbagi pengetahuan organisasi terhadap kinerja organisasi.

\section{Model Penelitian}

Berdasarkan pengembangan hipotesis yang sudah dibangun, maka hubungan hipotesis tersebut dapat dilihat $\underset{\mathrm{H}}{\mathrm{H}} \mathrm{a}$ gambar berikut ini:

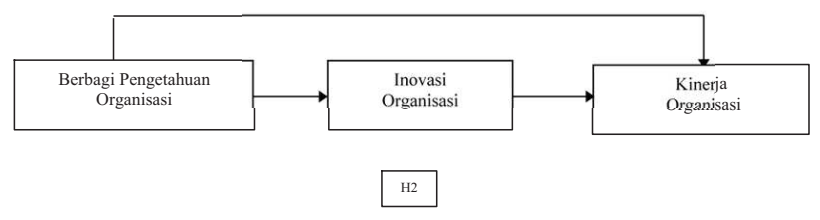

Gambar 1. Model Penelitian 


\section{METODE PENELITIAN}

Desain penelitian yang digunakan dalam penelitian ini adalah desain penelitian kuantitatif dan bersifat konfirmatori. Penelitian ini dilakukan dengan cara mengumpulkan dan mengolah data primer yang bersumber dari jawaban responden melalui penyebaran kuesioner, mengintepretasikan hasil penelitian dengan tujuan untuk menegaskan dan membandingkan dengan hasil penelitian terdahulu (Neuman, 2006). Penelitian ini melakukan konfirmasi terhadap peran pemediasi inovasi organisasi pada pengaruh berbagi pengetahuan organisasi terhadap kinerja organisasi. Jenis data yang digunakan dalam penelitian ini bersifat crosssectional yaitu jenis data yang dikumpulkan pada suatu waktu untuk menjawab pertanyaan atau pernyataan yang ada dalam kuesioner.

Sumber data dalam penelitian ini adalah data primer. Data primer dalam penelitian ini adalah data mengenai profil identifikasi responden yang dilihat dari sisi personal. Selain itu, data primer merupakan data yang digunakan untuk menjawab pertanyaan penelitian yang menyangkut data pengukuran persepsi responden tentang berbagi pengetahuan organisasi, inovasi organisasi, dan kinerja organisasi secara keseluruhan.

\section{Populasi, Sampel, dan Teknik Pengambilan Sampel}

Populasi dalam penelitian ini adalah dosen tetap yang bekerja pada Universitas yang ada di Indonesia. Mengingat besarnya jumlah data, maka penelitian ini menggunakan sampel untuk merepresentasikan populasi. Sampel dalam penelitian ini adalah dosen tetap yang bekerja di beberapa Universitas di Provinsi D. I Yogyakarta.

Teknik penyampelan dilakukan dengan metode purposive atau judgement sampling, untuk memastikan responden sesuai dengan tujuan penelitian ini (Cooper dan Schindler, 2011). Dalam pemilihan sampel dosen, kriteria yang digunakan dalam penelitian ini adalah pertama, dosen yang bekerja pada Universitas di Provinsi D. I Yogyakarta. Kedua, dosen tetap pada beberapa Universitas di Provinsi D.I Yogyakarta. Hal ini bertujuan agar memudahkan dosen dalam menilai penerapan berbagi pengetahuan selama berinteraksi dengan rekan kerjanya dan juga asumsi bahwa dosen telah memahami visi dan misi universitas dengan baik.

Unit analisis dalam penelitian ini adalah organisasi yang diwakili oleh dosen pada universitas di Provinsi D.I Yogyakarta. Dosen dipilih untuk menilai berbagi pengetahuan, inovasi organisasi serta kinerja organisasi secara keseluruhan. Metode penyampelan yang digunakan adalah nonprobability sampling. Sampel yang dipilih adalah dosen yang bekerja dalam universitas di Provinsi DI Yogyakarta. Dosen diminta untuk mengisi kuesioner yang menggambarkan berbagi pengetahuan organsisasi, inovasi organisasi dan kinerja organisasi.

Konstruk berbagi pengetahuan organisasi pengukurannya menggunakan kuesioner dengan 11 item pertanyaan. Konstruk inovasi organisasi pengukurannya menggunakan kuesioner inovasi organisasi yang terdiri dari 14 item pertanyaan. Konstruk kinerja organisasi pengukurannya menggunakan kuesioner yang terdiri dari 5 item pertanyaan. Dalam mengukur berbagi pengetahuan organisasi, inovasi organisasi, dan kinerja organisasi selama bekerjadi universitas dalam 3 tahun terakhir. Pernyataan-pernyataan dalam kuesioner diukur menggunakan skala likert dengan skala 1 sampai dengan 5 (1=sangat tidak setuju, 2=tidak setuju, 3=netral, 4=setuju, $5=$ sangat setuju) untuk menunjukkan tingkat penggunaan (frekuensi) responden terhadap pilihan jawaban. 
Tabel 1

\section{Definisi Variabel dan Konstruk Pengukuran}

\begin{tabular}{|c|c|c|c|}
\hline $\begin{array}{c}\text { Variabel } \\
\text { Penelitian }\end{array}$ & Definisi & $\begin{array}{c}\text { Indikator } \\
\text { Pengukuran }\end{array}$ & Kode \\
\hline $\begin{array}{l}\text { Berbagi } \\
\text { pengetahuan } \\
\text { organisasi }\end{array}$ & $\begin{array}{l}\text { Sebagai aktivitas } \\
\text { pertukaran } \\
\text { informasi, ide, } \\
\text { dukungan dan } \\
\text { keahlian antara } \\
\text { satu individu } \\
\text { dengan individu } \\
\text { yang lain dalam } \\
\text { suatu organisasi. }\end{array}$ & $\begin{array}{l}11 \text { Pertanyaan } \\
\text { (Allameh et } \\
\text { al., 2014) }\end{array}$ & BPO1-BPO11. \\
\hline $\begin{array}{l}\text { Inovasi } \\
\text { organisasi }\end{array}$ & $\begin{array}{l}\text { Sebagai sesuatu } \\
\text { yang baru atau } \\
\text { yang ditingkatkan } \\
\text { serta dilakukan } \\
\text { oleh organisasi } \\
\text { untuk menciptakan } \\
\text { nilai tambah } \\
\text { secara signifikan } \\
\text { baik secara } \\
\text { langsung untuk } \\
\text { organisasi atau } \\
\text { langsung bagi } \\
\text { pelanggan atau } \\
\text { konsumen. }\end{array}$ & $\begin{array}{l}14 \text { Pertanyaan } \\
\text { (Tuan et al., } \\
\text { 2016) }\end{array}$ & IO1-IO14. \\
\hline $\begin{array}{l}\text { Kinerja } \\
\text { organisasi }\end{array}$ & $\begin{array}{l}\text { Suatu perkiraan } \\
\text { yang luas } \\
\text { tentang persepsi } \\
\text { dari hasil kerja } \\
\text { organisasional. }\end{array}$ & $\begin{array}{l}5 \text { Pertanyaan } \\
\text { (Lee dan } \\
\text { Choi, 2003). }\end{array}$ & KO1-KO5 \\
\hline
\end{tabular}

\section{Metode Pengujian Instrumen}

Pengujian instrumen dilakukan untuk menguji apakah instrumen penelitian yang digunakan mampu untuk mengukur konstruk penelitian yang ingin diukur. Tahap ini meliputi uji validitas dan uji realibilitas.

Validitas ini sangat perlu dilakukan untuk menunjukkan sejauh mana instrumen penelitian dapat mengukur objek dalam penelitian secara tepat (Cooper dan Schindler, 2011). Pengujian validitas yang digunakan adalah pengujian validitas konstruk dengan menggunakan faktor analisis. Validitas akan diketahui dengan menghitung nilai factor loading. Factor loading adalah korelasi item-item pertanyaan dengan konstruk yang diukur. Menurut Hair et al. (2006) suatu instrumen riset dapat diterima jika nilai loading setiap item atau indikator terhadap variabel yang diukurnya adalah $\geq$ 0,4 . Jika factor loading suatu item mencapai $\geq$ 0,50, maka item tersebut sangat penting dalam menginterpretasikan konstruk yang diukurnya (Hair et al., 2006).

Uji reliabilitas berkaitan dengan akurasi dan presisis dari sebuah prosedur pengukuran (Cooper dan Schindler, 2011). Reliabilitas instrumen terdiri dari beberapa tipe yaitu reliabilitas stabilitas, kesetaraan (equivalence), dan konsistensi internal (Cooper dan Schindler, 2011). Reliabilitas instrumen yang diuji pada penelitian ini adalah konsistensi internal. Konsistensi internal mengukur tingkat yang mana item-item instrumen bersifat homogen dan mencerminkan konstruk yang sama (Cooper dan Schindler, 2011). Reliabilitas dianggap baik jika beberapa indikator yang berbeda dapat mengukur konstruk yang sama dan memberikan pengukuran yang sama (Neuman, 2006). Reliabilitas diuji dengan menggunakan Cronbach's alpha, dengan koefisien Cronbach's alpha minimal 0,6 (Hair et al., 2006).

\section{Metode Analisis Data}

Untuk menguji hipotesis dalam penelitian ini, peneliti menggunakan analisis regresi pemediasi (mediated regression analysis) yang telah dikembangkan oleh Baron dan Kenny (1986). Hipotesis penelitian diuji dengan rincian sebagai berikut: berikut:

Hipotesis 1 diuji menggunakan rumus $\mathrm{Y}=\alpha+\beta 1 . \mathrm{X} 1+\mathrm{e}$ persamaan 1

Hipotesis 2 diuji menggunakan rumus berikut:

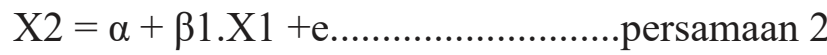

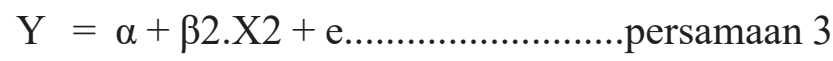

$$
\begin{aligned}
& \mathrm{Y}=\alpha+\beta 1 . \mathrm{X} 1+\beta 2 . \mathrm{X} 2+\mathrm{e} \ldots \ldots \ldots \ldots . . . \text { persamaan } 4
\end{aligned}
$$


Keterangan:

$\mathrm{Y} \quad=$ Variabel kinerja organisasi.

$a \quad=$ Konstanta regresi berganda

$\beta \quad=$ Nilai beta.

$\mathrm{X}_{1} \quad$ = Variabel berbagi pengetahuan

$\mathrm{X}_{2} \quad=$ Variabel inovasi organisasi.

$\mathrm{e} \quad=$ Error (variabel bebas lain diluar model regresi). maka:

Apabila dihitung dan diketahui hasilnya,

1. Apabila nilai $\beta 1$ (pada persamaan keempat signifikan), maka variabel pemediasi tersebut memediasi secara parsial.

2. Apabila nilai $\beta 1$ pada persamaan keempat (non-signifikan), maka variabel pemediasi tersebut memediasi sepenuhnya pada pengaruh positif variabel independen terhadap variabel dependen.

\section{HASIL PENELITIAN DAN PEMBAHASAN}

\section{Analisis Distribusi Kuesioner}

Pengumpulan data dilakukan dengan metode survei dengan instrumen penelitian berupa kuesioner. Kuesioner yang digunakan dalam penelitian ini berjumlah 75 responden. Responden mayoritas berjenis kelamin perempuan. Jumlah responden perempuan dalam penelitian ini berjumlah 45 orang $(60 \%)$ dan responden laki-laki berjumlah 30 orang $(40 \%)$. Ditinjau dari segi usia menunjukan bahwa usia yang mendominasi dalam penelitian ini yaitu 30-40 tahun berjumlah 52 orang $(69,33 \%)$, dan sisanya responden berumur 40-50 tahun berjumlah 23 orang $(30,67 \%)$. Tingkat pendidikan responden dalam penelitian ini yaitu sarjana (S2) sebanyak 59 orang $(78,66 \%)$ dan doktor (S3) sebanyak 16 orang $(21,34 \%)$.

\section{Uji Validitas}

Pengujian validitas instrumen dilakukan dengan analisis faktor terhadap butir-butir pernyataan kuesioner. Butir-butir pernyataan dikatakan mempunyai factor loading yang signifikan, apabila butir pernyataan tersebut memiliki skor factor loading $\geq 0,4$ dan skor factor loading tersebut tidak menjadi bagian atau anggota faktor lainnya. Hal ini menunjukkan bahwa indikator-indikator tersebut merupakan kesatuan alat ukur yang mengukur satu konstruk yang sama dan dapat memprediksi apa yang seharusnya diprediksi (Hair et al., 2006).

Sebelum melakukan analisis faktor, kriteria penting yang harus diperhatikan, yaitu hasil tes KMO dan tes Bartlett's. Kesimpulan tentang layak-tidaknya analisis faktor dilakukan untuk menguji suatu dimensi tertentu yang menggunakan uji Kaiser Meyer Olkin (KMO). Jika hasil yang ditampilkan oleh KMO dengan indeks di atas 0,05 maka analisis faktor untuk menguji item-item suatu dimensi tertentu layak untuk dilakukan (Hair et al., 2010).

Hasil uji KMO dan Bartlett's menunjukkan bahwa nilai KMO sebesar 0,750 dengan signifikansi 0,000 . Hal ini dapat disimpulkan bahwa uji analisis faktor telah memenuhi kriteria karena semua subvariabel atau item pengukuran layak sebagai faktor untuk masing-masing variabel yang diukurnya. Hasil KMO dan Bartlett's output SPSS 20.0 disajikan pada Tabel 1 di bawah ini: 
Tabel 1

\section{KMO dan Barlett's Test}

\begin{tabular}{|l|l|}
\hline \multicolumn{1}{|c|}{$\begin{array}{c}\text { Kaiser-Meyer-Olkin Measure of } \\
\text { Sampling Adequacy. }\end{array}$} &, 750 \\
\hline $\begin{array}{l}\text { Approx. Chi-Square } \\
\text { Bartlett's Test of Sphericity df } \\
\text { Sig. }\end{array}$ & 1529,202 \\
\hline
\end{tabular}

Sumber: data diolah (2017)

Tabel 2 menunujukkan hasil analisis faktor terhadap variabel berbagi pengetahuan organsiasi, inovasi organisasi, dan kinerja organisasi. Item IO3 dan IO8 secara statistik bukan merupakan pembentuk dimensi inovasi organisasi karena item IO3 cross loading pada faktor 3 dan item IO8 cross loading pada faktor 3 sehingga dinyatakan tidak valid. Item IO5 juga dinyatakan tidak valid karena memiliki factor loading yang tidak sesuai dengan kriteria dalam penelitian ini yaitu harus berada di atas 0,4 . Hasil analisis faktor pada konstruk berbagi pengetahuan organisasi dan kinerja organisasi menunjukkan tidak ada item pernyataan yang dibuang karena semuanya memiliki factor loading di atas 0,4.

\section{Uji Reliabilitas}

Reliabilitas suatu pengukur menunjukkan stabilitas dan konsistensi dari suatu instrumen mengukur suatu konsep atau suatu variabel (Cooper \& Schindler, 2006. Reliabilitas dapat diukur dengan melihat nilai Cronbach's alpha dan Composite reliability. Dalam penelitian ini, metoda pengujian reabilitas yang digunakan adalah Cronbach's alpha karena lebih baik dalam mengestimasi konsistensi internal suatu konstruk (Werts et al., 1974 dalam Salisbury et al., 2002).
Tabel 2

Hasil Analisis Faktor Berbagi Pengetahuan Organisasi, Inovasi Organisasi, dan Kinerja Organisasi

\begin{tabular}{|c|c|c|c|c|}
\hline \multirow{2}{*}{$\begin{array}{c}\text { Item } \\
\text { pertanyaan }\end{array}$} & \multicolumn{3}{|c|}{ Komponen } & \multirow[t]{2}{*}{ Keterangan } \\
\hline & 1 & 2 & 3 & \\
\hline BPO1 & 0,635 & & & Valid \\
\hline $\mathrm{BPO} 2$ & 0,817 & & & Valid \\
\hline BPO3 & 0,682 & & & Valid \\
\hline BPO4 & 0,787 & & & Valid \\
\hline BPO5 & 0,549 & & & Valid \\
\hline BPO6 & 0,681 & & & Valid \\
\hline BPO7 & 0,685 & & & Valid \\
\hline BPO8 & 0,752 & & & Valid \\
\hline BPO9 & 0,631 & & & Valid \\
\hline BPO10 & 0,719 & & & Valid \\
\hline BPO11 & 0,707 & & & Valid \\
\hline IO1 & & 0,741 & & Valid \\
\hline $\mathrm{IO} 2$ & & 0,722 & & Valid \\
\hline IO3 & & 0,437 & 0,467 & Tidak Valid \\
\hline $\mathrm{IO} 4$ & & 0,885 & & Valid \\
\hline IO5 & & 0,314 & & Tidak Valid \\
\hline IO6 & & 0,707 & & Valid \\
\hline IO7 & & 0,541 & & Valid \\
\hline IO8 & & 0,422 & 0,361 & Tidak Valid \\
\hline IO9 & & 0,724 & & Valid \\
\hline IO10 & & 0,885 & & Valid \\
\hline IO11 & & 0,408 & & Valid \\
\hline IO12 & & 0,461 & & Valid \\
\hline IO13 & & 0,645 & & Valid \\
\hline IO14 & & 0,737 & & Valid \\
\hline KO1 & & & 0,815 & Valid \\
\hline $\mathrm{KO} 2$ & & & 0,763 & Valid \\
\hline $\mathrm{KO} 3$ & & & 0,645 & Valid \\
\hline $\mathrm{KO} 4$ & & & 0,543 & Valid \\
\hline KO5 & & & 0,753 & Valid \\
\hline
\end{tabular}

Sumber: Data diolah (2017)

Suatu konstruk dikatakan reliabel jika memberikan nilai $\geq 0,60$ (Hair et al., 2006). Tabel 3 menunjukkan hasil pengujian reliabilitas 
Tabel 3

Pengujian Reliabilitas

\begin{tabular}{|l|c|c|}
\hline \multicolumn{1}{|c|}{ Variabel } & $\begin{array}{c}\text { Cronbach's } \\
\text { Alpha }\end{array}$ & Keterangan \\
\hline $\begin{array}{l}\text { Berbagi } \\
\text { Pengetahuan } \\
\text { Organisasi }\end{array}$ & 0.837 & Reliabel \\
\hline Inovasi Organisasi & 0.730 & Reliabel \\
\hline Kinerja Organisasi & 0.784 & Reliabel \\
\hline
\end{tabular}

Sumber: Data Diolah (2017)

Hasil penelitian ini menunjukkan bahwa nilai koefisien Cronbach's alpha untuk variabel berbagi pengetahuan organsasi adalah sebesar 0,837 , variabel inovasi organisasi sebesar 0,730 , dan variabel kinerja organisasi adalah sebesar 0,784 . Hal ini dapat disimpulkan bahwa jawaban setiap responden dari terhadap peryataan yang ada dalam variabel berbagi pengetahuan organisasi, inovasi organisasi, dan kinerja organisasi adalah konsisten sehingga membantu masing-masing item mengukur konsep yang diukurnya.

\section{Pengujian Hipotesis}

Hasil analisis regresi pemediasi untuk inovasi organisasi disajikan secara ringkas pada tabel 4 . Hipotesis 1 menyatakan bahwa berbagi pengetahuan organisasi berpengaruh positif terhadap kinerja organisasi. Hasil pengujian hipotesis pada tabel 4 menunjukkan bahwa berbagi pengetahuan organisasi memiliki pengaruh signifikan dan positif terhadap kinerja organisasi $(\beta=0.321 ; t=3.014 ; p<0,01)$. Hal ini berarti hipotesis pertama didukung.

Adanya dukungan positif dan siginfikan pada pengaruh berbagi pengetahuan organisasi terhadap kinerja organisasi ini berarti dosen dari beberapa Universitas di Provinsi Daerah Istimewa Yogyakarta memiliki kemampuan dalam menggunakan konsep berbagi pengetahuan dengan cara bertukar informasi, ide, pendapat, pengalaman, dan pengetahuan yang mereka miliki untuk menyelesaikan tugas dan meningkatkan kinerja dosen, sehingga secara bersama-sama dapat meningkatkan kinerja organisasi. Kemauan dosen dalam organisasi untuk saling bertanya, saling mengajarkan hal-hal baru dapat membantu organisasi dalam meningkatkan kinerja organisasi. Hal tersebut sejalan dengan penelitian empiris yang telah dilakukan oleh Allameh et al., (2014) bahwa berbagi pengetahuan organisasi memiliki pengaruh positif dan signifikan terhadap kinerja organisasi.

\section{Tabel 4}

\section{Hasil Analisis Regresi Pemediasi Inovasi Organisasi}

\begin{tabular}{|c|c|c|c|c|c|c|}
\hline \multirow{2}{*}{ Variabel Independen } & \multicolumn{3}{|c|}{ Kinerja Organisasi } & \multicolumn{3}{|c|}{ Inovasi Organisasi } \\
\hline & B & $\mathbf{T}$ & Sig. & B & $\mathbf{T}$ & Sig. \\
\hline $\begin{array}{l}\text { Tahapan } 1 \\
\text { Berbagi Pengetahuan } \\
\text { Organisasi (BPO) } \\
\mathrm{R}^{2}=0,125 \\
\Delta \mathrm{R}^{2}=0,125\end{array}$ & 0,321 & 3,014 & 0,003 & & & \\
\hline $\begin{array}{l}\text { Tahapan } 2 \\
\text { Berbagi Pengetahuan } \\
\text { Organisasi (BPO) } \\
\mathrm{R}^{2}=0,069 \\
\Delta \mathrm{R}^{2}=0,069\end{array}$ & & & & 0,341 & 2,363 & 0,029 \\
\hline $\begin{array}{l}\text { Tahapan } 3 \\
\text { Inovasi Organisasi } \\
\text { (IO) } \\
\mathrm{R}^{2}=0,173 \\
\Delta \mathrm{R}^{2}=0,173\end{array}$ & 0,358 & 3,192 & 0,002 & & & \\
\hline $\begin{array}{l}\text { Tahapan } 4 \\
\text { Berbagi Pengetahuan } \\
\text { Organisasi (BPO) + } \\
\text { Inovasi Organisasi } \\
\text { (IO) } \\
\mathrm{R}^{2}=0,323 \\
\Delta \mathrm{R}^{2}=0,323\end{array}$ & 0,313 & 2,542 & 0,014 & & & \\
\hline
\end{tabular}

Sumber: Data diolah (2017)

Hipotesis 2 menyatakan bahwa inovasi organsiasi memediasi pada pengaruh positif berbagi pengetahuan organisasi terhadap kinerja organisasi. Pada pengujian hipotesis dua ini, disajikan tiga hasil tahapan pengujian yang disyaratkan oleh Baron \& Kenny (1986) untuk membuktikan adanya suatu mediasi dalam suatu penelitian yaitu: pertama, hasil pengujian pengaruh positif berbagi pengetahuan organisasi dalam Universitas di Provinsi Daerah Istimewa 
Yogyakarta terhadap inovasi organsasi yang dirangkum dalam Tabel 4 menunjukkan adanya dukungan positif dan signifikan $(\beta=0.341$; $\mathrm{t}=$ $2,363 ; p<0,05)$. Hal ini berarti bahwa pengujian pada tahapan kedua didukung. Adanya dukungan pada pengaruh positif berbagi pengetahuan terhadap inovasi organisasi di beberapa Universitas di Provinsi D. I. Yogyakarta turut memperkuat hasil penelitian empiris yang telah dilakukan sebelumnya yaitu oleh Allameh et al., 2014) yang menjelaskan bahwa bahwa berbagi pengetahuan organisasi berpengaruh positif pada inovasi organisasi. Penelitian empiris ini juga turut mendukung penelitian yang dilakukan oleh Lin (2007) yang menyatakan bahwa individu yang ada dalam organisasi mampu mendorong untuk mengkontribusikan berbagi pengetahuan yang dimiliki ke dalam kelompok organisasi akan memiliki peluang yang lebih besar dalam meningkatkan kemampuan karyawannya dalam menciptakan ide-ide baru, mengembangkan peluang bisnis baru, sehingga pada gilirannya aktivitas tersebut akan mendorong peningkatan inovasi individu dan secara bersama-sama akan meningkatkan inovasi organisasi.

Pada tahapan pengujian kedua, pengujian pengaruh pengaruh positif inovasi organsiasi terhadap kinerja organisasi Universitas di Provinsi D.I Yogyakarta menunjukkan adanya dukungan positif dan signifikan $(\beta=0.358$; $\mathrm{t}=$ $3,192 ; p<0,01)$. Hal ini berarti tahapan ketiga didukung. Adanya dukungan pada pengaruh positif inovasi organisasi pada kinerja organisasi mendukung pendapat beberapa peneliti empiris terdahulu yang menjelaskan bahwa inovasi organisasi dapat meningkatkan kinerja organisasi (Tuan et al., 2016). Lebih lanjut Tuan et al., (2016) mengungkapkan bahwa inovasi organisasi merupakan sarana dalam meningkatkan keunggulan kompetitif suatu organisasi yang pada akhirnya dapat meningkatkan kinerja organisasi.
Pada tahap pengujian ketiga, hasil pengujian hipotesis pada tabel 4 menunjukkan bahwa inovasi organisasi memediasi sebagian (parsial) pada pengaruh positif berbagi pengetahuan organisasi terhadap kinerja organisasi $(ß 1=0,313 ; \mathrm{t} 1=2,542 ; \mathrm{p} 1<0,01)$. Hal ini menunjukkan nilai $\beta 1$ signifikan $(\mathrm{p} 1<0,01)$ yang berarti bahwa inovasi organisasi memediasi parsial pada pengaruh berbagi pengetahuan organisasi terhadap kinerja organisasi. Hal ini berarti hipotesis kedua didukung sebagian (parsial).

Adanya dukungan sebagian (parsial) pada pengaruh positif berbagi pengetahuan organisasi organisasi terhadap kinerja organasi yang dimediasi oleh inovasi organisasi menunjukkan bahwa berbagi pengetahuan organisasi yang menjadi variabel independen tidak serta merta langsung berpengaruh pada kinerja organisasi yang menjadi variabel dependen tetapi dapat melalui variabel inovasi organisasi yang bisa menjadi variabel pemediasi. Dalam penelitian ini, inovasi organisasi hanya memediasi secara parsial pada pengaruh berbagi pengetahuan organisasi terhadap kinerja organisasi menunjukkan akan adanya faktor lain yang bisa turut memediasi pengaruh hubungan tersebut, namun tidak menutup kemungkinan jika proses berbagi pengetahuan organisasi telah diterapkan dengan baik maka akan meningkatkan inovasi organisasi dalam perusahaan (Allameh et al., 2014) dan hasilnya akan meningkatkan kinerja organisasi (Tuan et al., 2016).

Adanya dukungan sebagian pada pengujian pengaruh positif berbagi pengetahuan organisasi terhadap kinerja organisasi yang dimediasi oleh inovasi organisasi sejalan dengan teori kapabilitas dinamis yang dikemukakan oleh Teece et al. (1997). Aktivitas berbagi pengetahuan dalam organisasi dapat meningkatkan inovasi organisasi yang merupakan salah satu kapabilitas dinamik organisasi sehingga pada akhirnya dapat 
meningkatkan optimalisasi sumber daya yang bernilai untuk mencapai keunggulan kompetitif organisasi (Teece, 2007), dapat membantu organisasi dalam menghadapi perubahan lingkungan organisasi yang semakin cepat (Birkinshaw et al., 2008), dan dapat meningkatkan kinerja organisasi (Tuan et al., 2016).

\section{KESIMPULAN DAN SARAN}

\section{Kesimpulan}

Berdasarkan hasil analisis dan pembahasan, maka dapat ditarik kesimpulan sebagai berikut: adanya dukungan pada pengaruh positif berbagi pengetahuan organisasi terhadap kinerja organisasi. Penelitian ini membuktikan bahwa semakin tinggi berbagi pengetahuan organisasi di dalam universitas maka hal ini kinerja organisasi akan meningkat. Melalui berbagi pengetahuan, dosen yang ada di universitas di provinsi D. I. Yogyakarta mampu mendorong keterlibatan dirinya dengan dosen lain terutama dalam bertukar pengetahuan, ide, gagasan yang menjadi tugas seorang dosen sehingga secara bersama-sama dapat meningkatkan kinerja organisasi. Hasil analisis menunjukkan bahwa adanya dukungan sebagian dalam pengujian pengaruh variabel pemediasi inovasi organisasi pada pengaruh positif berbagi pengetahuan organisasi terhadap kinerja organisasi. Melalui proses berbagi pengetahuan, dosen mampu mendorong keterlibatan dosen yang lain untuk bersama-sama untuk aktif dalam penerapan inovasi organisasi di universitas dan pada akhirnya dapat meningkatkan kinerja organisasi.

\section{Saran}

Berikut penulis sajikan saran-saran bagi penelitian selanjutnya terkait keterbatasan yang ada dalam penelitian ini:
1. Penelitian ini menggunakan teknik purposive sampling dengan akan lebih baik jika pada penelitian selanjutnya menggunakan jumlah sampel yang lebih banyak sehingga bisa digeneralisasi. Pada penelitian ini tidak semua sampel dalam populasi memiliki kesempatan yang sama untuk dipilih sebagai sampel, karena menggunakan teknik non random sampling. Konsekuensinya, generalisasi hasil penelitian harus dilakukan secara hati-hati. Oleh karena itu, penelitian yang akan datang sebaiknya menggunakan teknik random sampling sehingga tingkat generalisasi hasil penelitian menjadi lebih tinggi.

2. Untuk menambahkan nilai $\mathrm{R}^{2}$ penelitian selanjutnya bisa menambahkan variabel atau faktor lain yang mungkin dapat meningkatkan $\mathrm{R}^{2}$. Beberapa saran yang dapat digunakan antara lain faktor ukuran perusahaan (besar dan kecil). Faktor tersebut dapat dijadikan sebagai variabel moderasi.

\section{DAFTAR PUSTAKA}

Abdullah, R., Selamat, M. H., Azmi, J., Salfarina, A., dan Suaini, S. 2008. "An Empirical Study of Knowledge Management System Implementation in Public Higher Learning Institution". International Journal of Computer Science and Network Security, 8(1): 281-290.

Allameh S. M., Elham S. D. M. N., Shirin T. A dan Sayyedeh M. S. 2014. "Investigating the effects of knowledge sharing on innovation among managers of business organizations". International Journal of Management Academy. 2 (2): 1-9

Anthony R. N and V. Govindarajan, 2001. Management Control Systems, Tenth Edition, Chicago, Illinois: Ricard D. Irwin, Inc 
Baron, R. M., dan Kenny, D. A. 1986. "The moderator-mediator variable distinction in social psychological research: conceptual, strategic, and statistical considerations". Journal of Personality and Social Psychology 51, 1173-1182.

Birkinshaw, J.., J., Crainer, S., \& Mol, M. 2007. Special report on management innovation. Business Stategy Review, 18(1): 45-73.

Birkinshaw, J., Hamel, G. dan Mol, M. J. 2008. Management innovation. Academy of Management Review, 33,825-845).

Brigham, E. \& Ehrhardt, M. 2011. Financial Management: Teory and Practise, $13^{\text {th }}$ edition, Thomson, South Western.

Beal, D., Cohen, R.R., Burke, M.J., dan McLendon, C.L. 2003. "Cohesion and performance in groups: a meta-analytic clarification of construct relations". Journal of Applied Psychology, Vol. 88, pp. 989-1004.

Carnegie, R dan Butlin, M. 1993. "Managing the innovative enterprise". Mc.Kinsey \& Company.

Chan, A., Go, F., dan Pine, R. 1998. "Service innovation in Hong Kong: attitudes and practice". The Service Industry Journal, 18(2), 112-124.

Chaudhry, A.S. 2005. "Knowledge sharing practices in Asian institutions: a multicultural perspective from Singapore". Proceedings of the 7th IFLA General Conference and Council of the World Library and Information Congress, Oslo, Norway.

Chen, Yue-Yang., Huang, Hui-Ling., Yu, WanYu., dan Wei, Chung-Lun. 2011. "The fit effect model among facilitating factors on service innovation performance". World Academy of Science, Engineering and Technology 77.

Chiu. W.Y dan Chien. Y.C. 2015. The Effect of Knowledge-Sharing On Organizational Performance:

Organizational

Citizenship Behavior And KnowledgeAbsortion as mediators. International Journal of Information Technology and Business Management Vol 36. No1.

Christensen, Peter Holdt. 2005. "Facilitating Knowledge Sharing: A Conceptual Framework". Denmark, Center for Strategic Management and Globalization Copenhagen Business School.

Cohen, W. M., dan Levinthal, D. A. 1990. "Absorptive capacity: Anew perspective on learning and innovation". Administrative Science Quarterly, 35(1), 128-52.

Cooper., R.D., \& Schindler, P.S. 2011. Business Research Methods, $8^{\text {th }}$ ed., McGraw-Hill Education.

Delaney, J. T \& Huselid, M.A. 1996. The impact of human resource management practices in perceptions of organization performance. Academy of management Journal, 39: 949- 969.

Dalkir, K. 2005. "Knowledge Management in Theory and Practice". Oxford, UK: Burlington, MA.

Damanpour, F. dan Evan, V.M. 1984, "Organizational innovation and performance: the problem of organizational lag". Administrative Science Quarterly, Vol.29, pp. 392-409.

Darroch, J. 2005. "Knowledge management, innovation, and firm performance". Journal of Knowledge Management, 9: 101-115. 
Davenport, T.H., dan Prusak, L. 1998. "Working knowledge: how organizations manage what they know". Harvard Business School Press, Boston, MA.

Du Plessis, M. 2007. "The role of knowledge management in innovation". Journal of Knowledge Management, 11: 20-29.

Eisenhardt KM dan Martin J.A. 2000. Dynamic Capabilities; What are that? Strategic Management Journal, Winter Special Issues, 15, Hal. 1105-1121.

Fullwood, R., Rowley, J., dan Delbridge, R. 2013. "Knowledge sharing among st acade in UK universities". Journal of Knowledge Management, 17 (1): 123-136.

Grant, R. M. 1996. "Toward a knowledgebased theory of the firm". Strategic Management Journal, 17 (Winter Special Issue): 109-122.

Hair, J.F. Jr., Black, W.C., Babin, B.J., Anderson, R.E., dan Tatham, R.L. 2011. "Multivariate data analysis, $7^{\text {th }}$ ed". NJ, Person Practice Hall.

Hamel, G. 2006. The why, what, and how of management innovation. Harvard Business Review, 84, 72-84.

Hamel, G. 2007. The Future of Management. Boston, MA: Harvard Business School Press.

Hansen D. R \& Mowen, M.M. 2005. Management Accounting, $7^{\text {th }}$ edition, SouthWestern Publishing Co., Cincinnati.

Hsiu-Fen Lin, 2007. Knowledge sharing and firm innovation capability: an empirical study", International Journal of Manpower, Vol. 28 Iss: 3/4, pp.315 -332 .

Hu, Meng-Lei. Monica., Horng, Jeou-Shyan., dan Sun, Yu-Hua Christine. 2009. "Hospitality teams: knowledge sharing and service innovation performance". Tourism Management 30, 2009, 41-50.

Indarti, Nurul. 2010. "The effect of knowledge stickiness and interaction on absorptive capacity". University of Groningen, Groningen, The Netherlands.

Ipe, Minu. 2003. "Knowledge Sharing in Organizations: A Conceptual Framework". Human Resource Development Review 2003; 2; 337

Johannessen, J.A., B. Olsen., dan G.T. Lumpkin. 2001. "Innovation as newness: What is new, how new, and new to whom?". European Journal of Innovation Management 4: 20-31.

Jolaee, A., Khalil M. N., Naser, K., dan Rosman, M. Y. 2013. "Factors affecting knowledge sharing intention among academic staff'. International Journal of Educational Management, 28(4): 413431.

Kidwell, J. J., Linde, K. M. V., dan Johnson, S. L. 2000. "Applying corporate knowledge management practices in higher education”. Educause Quarterly, 3(4), 28-33.

Klijn, M., \& Tomic, W. 2010. A review of creativity within organization from a psychological perspective. Journal of Management Development, 29. 322343.

Lam, Alice., dan Ford, Jean-Paul Lambermont. 2008. "Knowledge Creation and Sharing in Organisational Contexts: A Motivation-based Perspective". The School of Management, Royal Holloway University of London.

Lee, J. N. 2001. "The impact of knowledge sharing, organizational capability and partnership quality on IS outsourcing 
success". Information \& Management 38 (2001) 323-35.

Lee, LT.S., and Choi, B. 2003. Knowledge management enablers, processes, and organizational performance: an integrative view and empirical examination. Journal of Management Information Systems, Vol.20, No.1, pp.179228.

Liao, Shu-hsien., Fei, Wu-Chen., dan Chen, ChihChiang. 2007. "Knowledge sharing, absorptive capacity, and innovation capability: an empirical study of Taiwan's Knowledge-intensive industries". Journal of Information Science, 2007; 33; 340

Liao, S., Wu, C., 2009. The relationship among knowledge management, organizational learning, and organizational performance. International Journal of Business and Management. Vol. 4 (4). Pp. 64-75.

Lin, Hsiu-Fen. 2007. "Knowledge sharing and firm innovation capability: an empirical study". International Journal of Manpower Vol. 28 No. 3/4. pp. 315332

Lundvall, B-Å. 1992. "National Systems of Innovation: Towards a Theory of Innovation and Interactive Learning". London: Pinter Publishers.

Mathew, V. 2010. "Service Delivery Through Knowledge Management In Higher Education". Journal of Knowledge Management Practice, 11(3): 1-15

Matzler, K., Renzl, B., Julia M, Herting, S., dan Mooradian, T.A. 2008. "Personality traits and knowledge sharing". Journal of Economic Psychology Vol. 29 pp.301-313.
Mohsen Allameh, Sayyed; Khazaei Pool, Javad; Jaberi, Akbar; Mazloomi Soveini, Farzaneh. (2014). Developing a model for examining the effect of tacit and explicit knowledge sharing on organizational performance based on EFQ approach. Journal of Science and Technology Policy Management. Bingley.5.3: 265-280

Neuman, W.L. 2006. Social Research Methods: Qualitative And Quantitative Approaches. 6th ed. Pearson Education.

Nonaka, I., dan Takeuchi, H. 1995. "The knowledge-creating company: How japanese companies create the dynamics of innovation". New York. Oxford University Press.

Nurmandi, Achmad, dan Umar. P. 2006. Implementasi knowledge management pada organisasi publik: Teori dan Kasus. Yogyakarta. Sinergi.

Polanyi, M. 1996. "The Logic of Tacit Inference". Philosophy, Vol. 41, No. 155, pp. 1-18.

Ramachandran, S. D., Chong, S. C. dan Ismail, H. 2009. "The practice of KM processes: a comparative study of public and private higher education institutions in Malaysia". The Journal of Information and Knowledge Management Systems, 39(3): 203-222.

Saad, A., dan Haron, H. 2013. "A Case Study of Academics' Knowledge Sharing Motivations at Malaysian Public Academic Institutions". Journal of Education and Vocational Research, 4(9): 265-274.

Sharratt, M dan Usoro, A. 2003. "Understanding Knowledge-Sharing in Online Communities of Practice”. European Journal of Knowledge Management, Vo1, paper 18 
Srivastava, Abhishek., Batol, Kathtyn. M., dan Locke, Edwin. A. 2006. "Empowering leadership in management teams: effects on knowledge sharing, efficiacy, and performance". Academy of Management Journal.Vol. 49, No. 6, 1239-1251.

Tuan, Nham; Nhan, Nguyen; Giang, Pham; Ngoc, Nguyen. 2016. The effects of innovation on firm performance of supporting industries in Hanoi, Vietnam. Journal of Industrial Engineering and Management; Barcelona. 9.2: 413431.

Teece, D.T., G. Pisano and A. Shuen, 1997. Dynamic capability and strategic management, Strategic Management Journal, Vol.18, No.7, pp.509-533.

Teece, D. J. 2007. Explicating dynamic capabilities: The nature and microfoundations of (sustainable) enterprise performance. Strategic Management Journal, 28, 1319- 50.

Teece, D. J and Augier, M. 2009. Dynamic capabilities and the role of managers. Organization Science 20(2), pp. 410-421.

Trehan, A., dan Kushwaha, P. S. 2012. "The implementation of Knowledge Management System in B-Schools". International Journal of Multidisciplinary Management Studies, 2(2): 252-260.

Vaccaro, G, Ignacio., Jansen, J, P, Justin., Van Den Bosch, A. J, Frans., Volberda, W, Henk. 2012. Management innovation and leadership: The moderating role of organizational size. Journal of Management Studies, 49: 29-47.

Venkatraman, N. And V. Ramanujam, 1986. Measurement of business performance in strategy research: A comparison approaches, Academy of Management Review, Vol, pp.801-814
Van den Hooff, B. dan J.A. de Ridder. 2004. "Knowledge sharing in context: the influence of organizational commitment, communication climate and CMC use on knowledge sharing". Journal of Knowledge Management 8:117-30.

Vries, R.E., B. Van de Hooff., dan J.A. de Ridder. 2006. Explaining Knowledge Sharing: The Role of Communiction Styles, Job Satisfaction, and Performance Belief. Communication Research, 33: 115-135.

Walker, Richard M., Damanpour, Fariborz., Devece, A, Carlos. 2010. Management innovation and organizational performance: The mediating effect of performance management, Journal of Public Administration Research and Theory, 4: 1-19.

Walz, S. M., dan Niehoff, B. P. 2000. "Organizational citizenship behaviors: their relationship to organizational effectiveness". Journal of Hospitality \& Tourism Research,24(3), 301-319.

Waterhouse, J. and A. Svendsen, 1998. Strategic performance monitoring and management; Using non financial measures to improve corporate governance, Quebec: The Canadian Institute of Charactered Accountant.

Xue, Y., J. Bradley., dan H. Liang. 2011. “Team Climate, Empowering leadership, and Knowledge Sharing". Journal Of Knowledge Management, emerald publishing. 